A LONGITUDINAL RESEARCH ON THE DEVELOPMENT OF EMOTIONAL

AUTONOMY DURING ADOLESCENCE (versión final publicada en 2009

http://dx.doi.org/10.1017/S1138741600001487 )

Agueda Parra \& Alfredo Oliva

Department of Developmental and Educational Psychology

University of Seville

June 2006

Correspondence:

Agueda Parra Jimenez

Dpto. Psicología Evolutiva y de la Educación. Universidad de Sevilla

Camilo José Cela s/n, 41018, Sevilla.

Tfno.: 0034954554333 Fax: 0034954559544

e-mail: aparra@us.es

This research was supported by grant BSO2022-03022 to the authors from the Spanish Ministry of Education, Culture and Sports. 
A LONGITUDINAL RESEARCH ON THE DEVELOPMENT OF EMOTIONAL AUTONOMY DURING ADOLESCENCE

June 2006 


\title{
A LONGITUDINAL RESEARCH ON THE DEVELOPMENT OF EMOTIONAL AUTONOMY DURING ADOLESCENCE
}

\begin{abstract}
The purpose of the present paper was to study the development of emotional autonomy through adolescence analysing its association with family relationships. The development of emotional autonomy involves an increase in adolescents' subjective sense of his or her independence, especially in relation to parents. From some scholars emotional autonomy is a normative manifestation of the detachment process from parents, however, others point out that detachment from parental ties is not the norm, so high level of adolescent emotional autonomy is the consequence of negative family relationships. In our study a sample of 101 adolescents were followed for 5 years, from early to middle adolescence, and completed questionnaires to measure their emotional autonomy and the quality of their family relationships. Our results showed that over the course of adolescence some dimensions of emotional autonomy increase, meanwhile others decrease, so the global level of emotional autonomy global level remains stable. On the other hand, emotional autonomy is associated with negative family relationships, so emotional autonomy, more than a necessary process to become adult, could be indicating an insecure attachment to parents.
\end{abstract}

KEY WORDS: Adolescence, Emotional autonomy, Family relationships, Longitudinal study 


\section{A LONGITUDINAL RESEARCH ON THE DEVELOPMENT OF EMOTIONAL AUTONOMY DURING ADOLESCENCE}

\section{INTRODUCTION}

Autonomy, within the framework of family relationships during adolescence, has been determined to be a construct with three closely related domains: a behavioural, a cognitive and an affective domain (Noom, Dekovic \& Meeus, 1999). Whereas the first of these domains refers to adolescents' capacity to act autonomously and make their own decisions; the second refers to a feeling of self-reliance and self-competence through which adolescents feel they are in control of their lives. Lastly, the third domain entails putting themselves at a certain emotional distance from their parents and establishing with them more symmetrical emotional bonds. Even if all three aspects are closely interconnected, emotional autonomy has probably aroused more interest among researchers in the last years causing, by the way, quite some controversy.

In the beginning of research on emotional autonomy, we can find the works published by psychoanalytical authors such as Anna Freud (1958) or Peter Bloss (1979), who consider that a certain break-up with and distancing from parents is an essential requisite for a healthy development during adolescence. A key issue within this theoretical framework is individuation, which refers to the act of disengaging from caregivers as a way for kids to "get out" of their family homes and establish close emotional relationships with other people. Rebellions against parents and more conflicts are an unavoidable consequence of this emotional disengagement which will necessarily require a readjustment of family relationships.

This perspective has strongly influenced the work by Steinberg and Silverberg who in 1986 published the first -and probably the most used scale in research work 
performed up to date- to assess emotional autonomy. They suggested that this construct has two components: one of a cognitive nature related to aspects such as the deidealization of parents, and another, of a more emotional nature, such as the feeling of independence and individuation. The cognitive component would entail a more realistic and less idealized viewpoint of parents, in which they are no longer the almighty people who know it all, but instead become normal people with their own set of virtues and flaws. On the other hand, the emotional component means that adolescents feel they are capable of managing themselves on their own without the constant support from their parents, making their own decisions and solving their own problems. Seen from this perspective, and as Peter Bloss or Anna Freud maintained, emotional autonomy is a necessary requisite to acquire adult roles and therefore there is nothing unusual in that it should increase with age. In this way, Steinberg and Silverberg (1986) found a significant increase in this variable throughout adolescence.

A different point of view was maintained by authors such as Ryan and Lynch (1989) who questioned the need for emotional disengagement for adolescent development. They considered that emotional autonomy from parents might be mirroring family dynamic problems that will not be of any help to the individuation process of the adolescent or to his/her well-being. In fact, and according to their theory, the scale created by Steinberg and Silverberg would not measure adolescents' emotional autonomy, but rather disattachment from their parents instead, which could be rooted in an insecure attachment during childhood.

In this same line of thought we can find other work highlighting the negative connection between family relationships quality and emotional autonomy (Von der Lippe, 1998; LoCoco, Pace, Zapulla \& Ignola, 2000; Oliva \& Parra, 2001), as well as between this variable and adolescent' wellbeing. According to these articles, a high 
emotional autonomy would be a consequence of an unsatisfactory family relationship, characterized by low support and confidence in the bond established with their parents and therefore related to a whole set of indexes resulting from poor adolescent adjustment. Other results supporting Ryan and Lynch's standpoint are those which have not found an increase in emotional autonomy with age (Fuhrman \& Holmbeck, 1995). In this sense, if emotional autonomy is a stable variable that remains constant throughout adolescence, then it would be a feature characterizing the functioning of certain family systems rather than a requisite for adulthood.

Our work has two aims. In the first place, we want to analyze, from a longitudinal perspective, how the emotional autonomy of a group of boys and girls evolves throughout adolescence, paying special attention to the paths followed by its partial components. On the other hand, we want to get know the connection between this emotional autonomy and other measures of family functioning. In fact, we expected to confirm, using a longitudinal perspective, the results of a previous cross-sectional study which showed that a high emotional autonomy was linked to poor family relationships (Oliva \& Parra, 2001).

\section{METHOD}

\section{Sample}

The work we here present comes forth from a research in which we used a crosssectional design to analyze the changes taking place in family dynamics coinciding with children's adolescence (Oliva \& Parra, 2001; Parra \& Oliva, 2002). In this research the sample consisted of 513 adolescents, 12 to 19 years of age and attending 10 schools of Seville and its province. Schools were selected using an intentional sampling (Moreno, Martínez \& Chacón, 2000) in which we deliberately tried to equate different 
characteristics of the sampling units as a way to obtain a sample as representative as possible depicting the different realities of our context. In this way, we took into account criteria such as school context -rural or urban-, ownership -state or semi private- and family socio-cultural level.

In the second stage of our research we monitored the youngest kids from the previous research project for more than five years. These adolescents completed our assessment tools in their early, middle and late adolescence, moments which we labelled Time 1-T1, Time 2 -T2- and Time 3-T3- respectively. The final sample consisted of 101 adolescents, 38 boys and 63 girls with an average age of 13.1 years (Sd $=.44)$ in $\mathrm{T} 1,15.4(\mathrm{Sd}=.56)$ in $\mathrm{T} 2$ and $17.8(\mathrm{Sd}=.52)$ in $\mathrm{T} 3$.

In order to identify possible differences between those adolescents who continued to be part of the study and those who did not, we carried out an atrittion analysis. Our results show that among the subjects remaining in the study there were a few more girls than boys, $\chi^{2}=4.05, p=<.05$, and less children of parents of a low educationalprofessional level, $\chi^{2}=6.52, p=<.05$. However, data were similar regarding context rural vs. urban-, and type of school attended -public vs. private-. No significant differences were found between the two groups in any of the variables related to family relationships or in emotional autonomy scores.

\section{Instruments}

1. Emotional Autonomy. Emotional Autonomy Scale (Steinberg \& Silverberg, 1986). We used a translation made by the research team members following the Double Translation Method. Likert type scale -from 1 to 4- with 20 items. The scale's reliability for each of the measuring times is as follows: Cronbach alpha T1 / T2 / $\mathrm{T} 3 \square=.66 / .75 / .79$. This instrument is comprised of four dimensions, two of an 
emotional nature and two of a cognitive one. Emotional domains are Individuation, Cronbach alpha T1 / T2 / T3 $\square=.44$ / .65 / .80, and Independency, Cronbach alpha $\mathrm{T} 1 / \mathrm{T} 2 / \mathrm{T} 3 \square=.48 / .56 / .52$, and both refers to the emotional separation from parents needed to act in an autonomous way. Cognitive domains involve the belief that parents are normal and ordinary people who have their own needs and desires. Specifically, authors distinguish as cognitive factors the Deidealization, Cronbach alpha T1 / T2 / T3 $\square=.63$ / .67 / .66, and Parents as normal people, Cronbach alpha $\mathrm{T} 1 / \mathrm{T} 2$ / T3 $\square=.37 / .42 / .41$.

2. Parenting styles. We used as our basis the instrument by Lamborn, Mounts, Steinberg \& Dornbusch (1991). We used a translation made by the research team members following the Double Translation Method. It includes the Acceptance/involvement scales, Cronbach alpha T1 / T2 / T3 $\square=.69 / .68 / .76$, and Supervision/Monitorization, Cronbach alpha T1 / T2 / T3 $\square=.74$ / .71 / .62.

3. FACES II. Family Adaptability and Cohesion Scale, (Olson, Portner \& Lavee, 1985). We used a translation made by the research team members following the Double Translation Method. This is a scale created to assess family relational structures. It consists of 30 likert type items rated from 1 to 5 which allows for the evaluation of Cohesion, Cronbach alpha T1 / T2 / T3 =.69 / .84 / .87, and Adaptability, Cronbach alpha T1 / T2 / T3 =.71 / .74 / .81, in family relationships.

4. Family Communication. (Parra \& Oliva, 2002) Scale created for this research study comprising 22 items, 11 related to fathers and 11 related to mothers, evaluating family communication frequency on several issues; friends, free time, sexuality, drugs, future plans, etc. Likert type scale rated from 1 to 4 , where 1 means that they never talk about this issue and 4 that they talk about it frequently. Cronbach alpha for Communication with mothers T1 / T2 / T3 =.78 / .78 / .83; Cronbach alpha for 
Communication with fathers $\mathrm{T} 1 / \mathrm{T} 2 / \mathrm{T} 3=.79 / .82 / .82$. Due to the high correlation found between communication with mothers and with fathers, we generated a Communication variable to simplify data obtained. This variable was generated through the average scores obtained in communication with both parents.

5. Conflicts between parents and adolescents (Parra \& Oliva, 2002). With a pattern similar to the scale above, this is a scale of 14 items assessing the frequency of conflicts between parents and adolescents on a number of issues: curfew time, friends, drugs, politics or religion, etc. A likert type scale is used rated from 1 to 4 , in which 1 means not having any arguments and 4 having frequent arguments. Cronbach alpha $\mathrm{T} 1 / \mathrm{T} 2 / \mathrm{T} 3=.86 / .65 / .74$

\section{Procedure}

Our first step was to select the schools for our study and contact their management board to give them information about our research and request their collaboration. Once they agreed to participate in our study, we selected the classrooms where we would collect our data. We then sent a letter to the adolescents' parents asking for their permission to include their children in our study. It is important to point out that we did not receive a single refusal to participate in our study. Once we received their consent, we administered our questionnaires collectively.

Two years later-T2- and coinciding with middle adolescence, we contacted subjects again. We went back to the schools and there we interviewed adolescents collectively. Lastly, the third data collection -T3- was performed when subjects were in their late adolescence. Some did not attend school anymore or attended schools different from those in $\mathrm{T} 1$, so in these cases we contacted them and once they agreed to participate, we arranged an appointment for them to fulfil the questionnaire in the 
seminar of the Department of Developmental and Educational Psychology of the University of Seville.

\section{RESULTS}

Our first aim in this study was to analyze emotional autonomy from a longitudinal perspective and with this in mind we will present our results distinguishing between its absolute and relative stability. This distinction is a cornerstone of longitudinal studies which take into account the effect of the time factor on the variables of a single group of subjects (Stoolmiller \& Bank, 1995). The absolute stability of a variable entails analyzing how its average value reacts in the different measuring times. Since this is based on average scores, this analysis does not offer us information on the possible different paths followed by subjects. With the aim of going into this aspect in depth, we analyzed relative stability. Relative stability provides information on the consistency of subjects' placement regarding their reference group. The procedure most commonly used to measure relative stability is one based on the correlation coefficients between different measuring times (Alder \& Scher, 1994).

\section{Absolute stability of Emotional Autonomy}

A group of repeated measures analysis of variance (ANOVA) was conducted to investigate the Absolute stability -the possible effect of time on Emotional Autonomy-. Total scores and scores obtained for each subscale of emotional autonomy were considered dependent variables. Factors included in each ANOVA were Time (intraindividual factor of repeated measures varying on three levels) and Sex (interindividual factor). We used Mauchly's test to confirm the sphericity of variancecovariance matrices and Levene's test for homogeneity. In those cases in which some of 
these assumptions were not met, we also used the univariate F-statistics after applying the Greenhouse-Geisser epsilon correction factor (1959).

When we analyzed the development of Emotional Autonomy, even if there was a slight increase, no significant differences were found depending on time $F(1.5,98)=1.71$, n.s, (observed power $=.34$ ), or sex, $F(1,99)=0.01$, n.s, (observed power=.05). No significant interaction effects were found either between both factors, $F(1.85,98)=.48$, n.s, (observed power $=.12)$.

In order to analyze possible paths different from those represented by average scores, we carried out a cluster analysis using emotional autonomy scores in T1, T2 and T3. We first used a K-means analysis that reduced the total number of subjects to 10 groups. We then performed a hierarchical cluster analysis of these 10 groups after which we decided to choose 3 of them. Paths followed by these three groups can be seen in Figure 1.

\section{Paste figure 1, approximately here}

Group 1, which was the most numerous, had a low emotional autonomy which remains relatively constant throughout the years. Group 2 however showed an important decrease between early and middle adolescence. Lastly, group 3, formed by boys and girls who were more emotionally autonomous, increases as age does. These results prove that even if emotional autonomy had a high absolute stability for most subjects there were more subjects in group 1-, some adolescents experienced certain changes and this varied absolute stability results. On the other hand, boys and girls were represented equally in all three groups, $\chi^{2}=1.35$, n.s., which confirmed the absence of gender based differences revealed in the analysis of repeated measures. There was no differences either between the three groups regarding family structures, $\chi^{2}=2.35$, n.s., education 
level of mothers, $\chi^{2}=4.16$, n.s., and of fathers, $\chi^{2}=1.18$, n.s., or in the type of context rural vs. urban-, $\chi^{2}=.24$, n.s.

\section{Emotional Autonomy's relative stability}

As was revealed by Table I, the relative position filled by boys and girls was very stable throughout the years, especially so between middle and late adolescence. Correlation between both times is .66 , which means that the emotional autonomy score in T2 explained about $44 \%\left(R^{2}\right)$ of the scores of subjects in T3. Greater stability between middle and late adolescence could also be seen in the cluster analyses performed showing less changes in these years than during previous years. In fact, low relative stability could be a consequence of there being subjects whose scores decreased between early and middle adolescence-group 2-, whereas other's scores increased groups 1 and 3.

\section{Trends followed by emotional autonomy domains}

\section{1) Absolute stability}

a) Emotional Domains

- Individuation

This domain includes items such as: "When someday I become a father/mother I will do certain things differently from how my father/mother did them to me" or "There are some things my parents don't know about me". Through them we intended to learn whether these adolescents had a self-image in which they were people with features different from their parents, and if in their role as future parents they would behave differently from their parents or not . 
As can be seen in Figure 2.a, the feeling of Individuation of boys and girls in our study did not change throughout the years, $F(2,98)=.43$, n.s., (observed power $=.12$ ). There was no significant differences either between boys and girls, $F(1,99)=.44$ $($ Observed power $=.10)$, or interaction effects, $F(2,98)=1.38$, n.s. $($ observed power $=$ $.28)$.

- Independence

There was five items evaluating Independence. All of them inquired, in one way or another, about the adolescent's ability to fend for him or herself in difficult situations without necessarily relying on his/her parents' support or opinion.

There was an increase over the years in the Independence factor of the Emotional Autonomy scale -please see Figure 2.b-, $F(1.72,98)=10.73, p<.001$, eta $^{2}=$ 10. In the case of boys there was a significant increase between T1 and T2, $p<.01, d=$ .59. In the case of girls, however, significant differences where found when comparing T1 with T3, p <.05, $d=.38$.

No significant sex based differences were found, $F(1,99)=.80$, n.s (observed power $=.14)$. There were no significant interaction effects either, $F(1.72,98)=1.00$ (observed power $=.20)$.

b) Cognitive Domains

\section{- Deidealization}

This domain comprises items such as: "My fathers never make mistakes" or "When someday I become a parent I will treat my children in the exact same way my parents treat me". Results showed that there was no significant differences between boys and girls regarding the Deidealization of their parents, univariate contrast $F(1,99)=1.95, p=$ n.s. $($ observed power $=.28)$. Furthermore, both boys and girls showed a significant increase in this variable over the years, $F(1.85,98)=11.02, p<.001$, eta $^{2}=$ 
17. The increase for boys happened between $\mathrm{T} 2$ and T3, $p<.01, d=.46$; for girls, the increase was only significant between $\mathrm{T} 1$ and $\mathrm{T} 3, p<.01, d=.45$.

Interaction effects between time and sex factors were not significant (observed power $=.08)-$ Please see Figure 2.c-.

\section{- Parents perceived as "normal" people}

This scale included the following type of items: "I have sometimes wondered how my parents behave and what they do when I am not with them" or "The things my parents speak about are probably different when I am with them and when I am not".

As years go by there was a significant decrease in adolescents' concern about how their parents were out of home, beyond their roles as parents, $F(2,98)=8.20$, $p<.001, e t a^{2}=.12$, for both boys and girls. For the former we found a significant decrease between $\mathrm{T} 1$ and T3, $p<.01, d=.63$, and for the latter between T1 and T2, $p<$ $.01, d=.47$.

Data showed significant differences between both groups, $F(1,99)=9, p=<.01$, $e t a^{2}=.08$ as boys had higher scores than girls in early and middle adolescence -please see Figure 2.d-.

\section{Paste Figure 2 approximately here}

\section{2) Relative stability}

Correlations depicted in Table II show that the stability of the different elements of Emotional Autonomy ranged from average to high throughout the years. The relative stability of the Independence domain was somewhat lower between early and middle adolescence even if, as also happened for the other three domains, stability between early and middle adolescence was higher. This revealed that those boys and girls who showed, for example, that they were more independent from their parents in their middle adolescence were also the ones who were more independent during their late 
adolescence. Something different happened in the domain of Parents as normal people, and in this case, relative stability was slightly higher between early and middle adolescence than between middle and late adolescence.

Paste Table II approximately here

\section{Connections between emotional autonomy and family functioning}

The second aim of our work was to analyze the connection between emotional autonomy and different measures of family functioning. As shown in Table III, emotional autonomy had strong connections to different family functioning measures throughout all adolescence. As emotional autonomy increased, communication with parents decreased and the frequency of conflicts rose. Those boys and girls who were more autonomous were the ones who felt less cohesion, adjustment and caring at home, and who felt greater parental psychological control.

Paste Table III approximately here

It is important to point out that, in years later, the nature of family relationships remained to be related to the emotional autonomy experienced during adolescence. It thus happened, for example, that communication problems or lack of affection experienced during early adolescence was connected to less emotional autonomy not only 2 years later, during middle adolescence, but also during late adolescence. Similarly, difficult family relationships during middle years were related to adolescents' greater autonomy in their late adolescence.

Bearing in mind the relations among family functioning measures, we used a principal components analysis (varimax rotation) to reduce information on family relationship variables. In this factor analysis, we took into the account the following 
variables: affection, control, cohesion, adaptability and communication with parents. The conflicts variable did not offer information for the factorial solution so we decided to analyze its relation to emotional autonomy separately. In T1 the only factor extracted explained $43.4 \%$ of the total variance. In T2 this percentage increased to $47.8 \%$ and in T3 to 53.2\%. These factors were labelled Quality of family relationship in T1, Quality of family relationship in $T 2$ and Quality of family relationship in $T 3$.

We analyzed, through an ANOVA with repeated measures the scores obtained throughout adolescence by the different subjects groups (created with the cluster analysis; remember Figure I) for the variable Quality of family relationship. We found significant differences in the paths followed by the 3 groups as significant interaction effects showed, $F(3.77,96)=4.55, p<.01$, $e t a^{2}=.08$. In this manner, those adolescents whose emotional autonomy increased as age did had a more negative family environment which worsened over the years $F(1.99,98)=7.34, p<.01$, eta $^{2}=.30$. No significant changes were found during adolescence in the other two groups regarding Quality of family relationship (observed power $=.17$ and .23 , respectively). As can be seen in Table IV, significant differences appeared in the three stages of adolescence between the three different groups regarding Quality of family relationship scores. Post-hoc analysis revealed that during early adolescence there were main differences between groups 1 and $2(p<.01, d=.87)$ and groups 1 and el $3(p<.05, d=.96)$, whereas during middle adolescence differences were found between groups 3 and 1 ( $p<$ $.01, d=.99)$ on the one hand, and groups 3 and $2(p<.05, d=1.12)$ on the other. Significant differences appeared again during late adolescence between groups 3 and 1 $(p<.01, d=1.10)$ and groups 3 and $2(p<.01, d=1)$.

In any case, in all three stages of adolescence, adolescent boys and girls with lower emotional autonomy levels were the ones describing a higher quality of family 
relationship, whereas those adolescents who report living in a more difficult environment are the ones with higher emotional autonomy levels.

Paste Table IV approximately here

\section{DISCUSSION}

To our understanding, our work offers two main contributions which are related to its longitudinal nature. In the first place, the thorough analysis our work performs regarding the development of emotional autonomy throughout adolescence, taking into account not only the overall score of the construct, but also the trends followed by its partial domains. In the second place, the analysis here presented from a longitudinal perspective on the connection between adolescent emotional autonomy and relationships taking place at the heart of family life.

Regarding the development of emotional autonomy in the second decade of life, our data show that it remains quite stable over the years. Most boys and girls report similar autonomy levels from their families at early, middle and late adolescence. However, the partial domains making up emotional autonomy, two of which are of a cognitive nature -Deidealization and Parents as normal people- and two of an emotional nature -Individuation and Independence- revealed less stability than the overall index. The fact that the overall emotional autonomy index remains stable, whereas its related domains vary, might seem contradictory. We nevertheless consider this not to be a contradiction, but an evidence that the instrument designed by Steinberg and Silverberg does not only measure a single construct, but rather evaluates different aspects which do not necessarily have to follow a single path, something which by the way complies with what our results indicate. Therefore, by analyzing the trends followed by these domains over the years, we were able to learn that boys and girls of our sample have a more realistic and less idealized view of their parents as years go by, and that they reveal a 
more independent attitude, feeling increasingly more capable of facing different life situations without their parents' help.

On the other hand, individuation is related to whether or not adolescents consider themselves to be people who have different features from those of their parents, and capable of analyzing how their parents have brought them up and of finding in this analysis both positive and negative aspects. Continuity seen in this domain might be a result of this aspect being reached by most children at early adolescence, and not changing significantly with age.

As for the development of the domain of perceiving Parents as normal people, our data point out that this is an aspect which decreases with age. At first, these results might seem surprising; however, when they are seen in further detail, they might make a lot of sense. This cognitive domain implies having certain concerns about how parents will behave outside their parental role, how they would act, let's say, at a party or with other relatives. This concern will probably be higher during the first years of adolescence, and as kids discover that their parents are people having their own lives, they would stop worrying about whether they behave similarly at home and at work, or if they talk about other issues depending on whether or not their children are present . In this same sense, it would not be strange either to think that if parents behave differently depending on whether or not their children are present, and are, for example, more careful not to talk about certain issues, such as alcohol consumption or sex, this would happen more during childhood and the first years of adolescence. The low correlation found between this domain and the other three, as well as its downward trend, seriously questions the convenience of including these contents in the emotional autonomy scale, something already proposed by other authors (Beyers, Goossens, Vansant and Moors, 2003). 
In spite of the high stability found in emotional autonomy seen globally, our analyses have identified groups following less stable paths. The ones experiencing more changes are those who score higher in this variable at early adolescence. These youngsters, who are more autonomous at early adolescence, can be divided into two groups: one following an upward trend over the years; and another experiencing a downward motion placing them at levels similar to those of their less autonomous peers. It is interesting to note that according to our data, an increase in emotional autonomy entails a worsening of adolescents' relationships with their parents, whereas its decrease over the years seems to be related to an improvement of these relationships. As we can see, emotional autonomy is related to difficult family functioning. It is therefore no surprise that two distinctive groups should appear from the beginning of adolescence depending on their scores on this variable. A majority group with low levels and positive relationships with their parents, and another less numerous group with higher scores reflecting interactions that might be more complicated. If we take into account that the first years of adolescence represent a period of instability for the family system demanding adjustment efforts on the part of its members (Granic 2000), it is then no wonder that in our results there should be a group of adolescents that at this time shows high emotional autonomy levels and that these will later decrease. It might be the case that the normalization of family life and the establishment of a new balance are related to a later decrease in their emotional autonomy, since as our results seem to show, high emotional autonomy levels are linked to more difficult, and somewhat more conflictive, family environments. Other adolescents, however, will continue to have difficult relationships with their parents throughout adolescence, and this will be reflected in their higher autonomy levels as compared to their peers. 
If early adolescence is the most unstable moment within the family system (Collins, 1995), the high emotional autonomy of certain adolescents who are still developing a process of negotiation with their parents might be an answer to these troublesome relationships. In as far as a new balance is attained, this group of adolescents will see their emotional autonomy decrease to the levels of the majority. In any case, there will always be a less minority group whose family relationships will remain being difficult, and who will show a higher autonomy level.

These results, especially those concerning a higher absolute stability of emotional autonomy, do not match those results obtained by the creators of the scales showing an increase in this variable over the years (Steinberg and Silverberg, 1986). Emotional autonomy for these authors is an essential requisite for adolescent development. If boys and girls do not establish a certain emotional distance from their parents, their emotional development process might be compromised. In this way, being emotionally autonomous would be a positive contribution to the adolescents' well being and a guarantee of independent and mature development. For other authors, such as Ryan and Linch (1989), on the contrary, this would not be a normative aspect of adolescent development but instead a consequence of difficult family relationships, maybe of an insecure attachment bond. From this perspective, the most autonomous boys and girls would be the ones maintaining more negative relationships with their parents, so that their emotional disengagement from them would be the answer to these difficult and hostile interactions at home.

Our results fall more in line with this second way of understanding emotional autonomy, and matches those of other research performed in Europe (von der Lippe, 1998; LoCoco et al., 2000). Adolescents who show higher emotional autonomy levels 
are the ones having more difficult relationships with their parents, characterized by frequent conflict, lack of communication and low levels of cohesion.

So in summary, we could say that according to our data and taking into account the connection there is between emotional autonomy and family functioning, we doubt this is a requisite for disengagement from parents or a necessary step to become an independent adult. Our results lead us rather to believe that at least among the boys and girls of our sample, this mirrors difficult family relationships. What probably promotes an optimum development is autonomy combined with positive interpersonal bonds. Consequently, one of the main personal goals to be attained by boys and girls during adolescence is to develop themselves as autonomous individuals who are capable at the same time to keep positive relationships with others, especially with their mothers and fathers.

For some years now various researchers have been wondering about the role played by socio-cultural variables in emotional autonomy, and more specifically about their impact on the well being of boys and girls (Cooper, 1994; Feldman and Rosenthal, 1991; Kagitcibasi, 1996). According to these articles, it is reasonable to think that emotional disengagement from parents does not have the same meaning in societies such as that of the United States, where independence and autonomy are highly valued aspects, as it has in other societies such as Mediterranean ones in which families play a much more central role, and in which keeping close bonds with mothers and fathers is something considered to be basic. Maybe, as Kagitcibasi (1996) has pointed out, to consider that autonomy is a result of a process of individuation or of emotional separation from one's family might only make sense in very individualistic cultures. In more collective cultures, like ours, keeping close emotional bonds with mothers and fathers is probably a requisite for healthy development. 
In line with information presented by other authors (Andersen, La Voie and Dunkel, 2007; Schmitz and Baer, 2001), our results also bind us to consider whether the instrument designed by Steinberg and Silverberg (1986) is the best option to evaluate Emotional Autonomy given that it might not be measuring this construct, but rather an index for certain disattachment from parents instead. On the other hand, the low reliability levels of its four subscales, especially for early adolescence, lead us to consider the comprehension difficulty posed by these items for younger adolescents. However, we must point out that during middle and late adolescence, Cronbach alpha indexes in our study reached average levels similar to those described by Steinberg and Silverberg (1986) in their work. In this sense, and following Arnett (2000), autonomy would not be something completed during adolescence but rather something which continues to be forged years later. We are conscious, nevertheless, of the need to continue considering that the concept of emotional autonomy is twofold, and to be more precise when it is defined operatively, creating instruments with rigorous psychometric properties to measure it.

One of the main shortcomings of our work is related to the exclusive use of questionnaires to collect information. In like manner, obtaining several measures from one single informant increases the number of correlations between such measures. In spite of all of this, the use of questionnaires is a frequent methodology used in developmental psychology, and compared to other resources of a more qualitative nature they have undeniable advantages such as the use of standardized and validated tests that offer the possibility of comparing different subjects. On the other hand, even if 101 subjects is a significant number if we take into account the longitudinal nature of our research, it is also true that it is not a numerous sample, and that it has, to a certain extent, conditioned the statistical analyses conducted. In fact, we are conscious that it is 
difficult to generalize our results, especially those related to boys since there were fewer boys than girls in our study.

In spite of these limitations, we would like to highlight that our work is one of the few longitudinal studies performed in Spain which covers more than five years of adolescent development. This longitudinal perspective is the one which allows us to learn in further detail about emotional autonomy and to point to possible causal connections. We believe that more research using this type of design is needed in order to shed some light on the changes taking place within emotional autonomy during the years of adolescence, and on its true meaning for the well being of boys and girls. In so far as new research is performed within our field, we will be better prepared to state with greater certainty, as our results reveal, that emotional autonomy is not as much a sign of girls and boys' maturity as an expression of the quality of their relationships with their parents.

\section{REFERENCES}

Alder, A. G., y Scher, S. J. (1994). Using growth curve analyses to assess personality change and stability in adulthood. En Heatherton, T. F. y Weinberger, J. L. (Ed.), Can personality change? Washington, DC: American Psychological Association.

Andersen, B., La Voie, J.C. y Dunkel, C.S. (2007). Individuation and parents as people: Measurement concerns regarding two aspects of autonomy. Journal of Adolescence, 30, 751-760.

Arnett, J. (2000) Emerging adulthood: A theory of development from the late teens through the twenties. American Psychologist, 55, 469-480. 
Beyers, W., Goossens, L., Vansant, I., y Moors, E. (2003). A structural model of autonomy in middle and late adolescence: Connectedness, separation, detachment, and agency. Journal of Youth and Adolescence, 32(5), 351-365.

Beyers, W., y Goossens, L. (1999). Emotional autonomy, psychosocial adjustment and parenting: interactions, moderating and mediating effects. Journal of Adolescence, 22, 753-769.

Blos, P. (1970). The young adolescent. New York: Free Press.

Chen, Z., y Dornbusch, S. M. (1998). Relating aspects of adolescent emotional autonomy to academic achievement and deviant behavior. Journal of adolescent research, 13(3), 293-319.

Collins, W. A. (1995). Relationships and development: Family adaptation to individual change. En Shulman, S. (Ed.), Close relationships and socioemotional development (pp. 128-154). New York: Ablex.

Cooper, C. R. (1994). Cultural perspectives on continuity and change in adolescents' relationships. En Montemayor, R., Adams, G. R., y Gullotta, T. P. (Ed.), Personal relationships during adolescence. (pp. 78-100). Thousand Oaks, CA: Sage.

Feldman, S., y Rosenthal, D. A. (1991). Age expectations of behavioral autonomy in Hong Kong, Australian, and American youth: the influences of family variables and adolescents' values. International Journal of Psychology, 26, 1-23.

Freud, A. (1958). Adolescence. Psychoanalytic study of the child, 13, 255-278.

Fuhrman, T., y Holmbeck, G. N. (1995). A contextual-moderator analysis of emotional autonomy and adjustment in adolescence. Child Development, 66, 793-811.

Granic, I. (2000). The self-organization of parent-child relations: Beyond bidirectional models. En M. D. Lewis, y Granic, I. (Ed.), Emotion, development, and self- 
organization: dynamic systems approaches to emotional development (pp. 267297). New York: Cambridge University Press.

Greenhouse, S. y Geisser, S. (1959). On methods in the analysis of profile data. Psychometrika, 24, 95-111.

Kagitcibasi, C. (1996). The autonomous-relational self: A new synthesis. European Psychologist, 1, 180-186.

Lamborn, S. D., Mounts, N. S., Steinberg, N. L. y Dornbush, S. M. (1991). Pattern of competence and adjustment among adolescents from authoritative, authoritarian, indulgent and neglectful families. Child Development, 62, 1049-1065.

LoCoco, A., Pace, H., Zapulla, C. y Ignola, S. (2000). Emotional autonomy in Italian adolescents. Poster presentado en el VII Congreso Bianual de la EARA, Jena (Alemania).

Moreno, R., Martínez, R. J. y Chacón, S. (2000). Fundamentos metodológicos en psicología y ciencias afines. Madrid: Pirámide.

Noom, M. J., Dekovic, M., y Meeus, W. (2001). Conceptual analysis and measurement of adolescent autonomy. Journal of Youth and Adolescence, 30(5), 577-595.

Oliva, A., y Parra, A. (2001). Autonomía emocional durante la adolescencia. Infancia y aprendizaje, 24, 181-196.

Olson, D. H., Portner, J. y Lavee, Y. (Ed.). (1985). Family Adaptability and Cohesion Scale. Minneapolis: University of Minnesota.

Parra, A., y Oliva, A. (2002). Comunicación y conflicto familiar durante la adolescencia. Anales de psicología, 18, 215-231.

Ryan, R. M., y Lynch, J. H. (1989). Emotional autonomy versus detachment: revisiting the vicissitudes of adolescence and young adulthood. Child development, 60, 340-356. 
Steinberg, L., y Silverberg, S. (1986). The vicissitudes of autonomy in early adolescence. Child Development, 57, 841-851.

Schmitz, M.F. y Baer, J.C. (2001). The vicissitudes of measurement: A conflirmatory factor análisis of the emocional autonomy scale. Child Development, 72, 207219.

Stoolmiller, M., y Bank, L. (1995). Autoregressive Effects in Structural Equation Models: We See Some Problems. En Gottman, J. M. (Ed). The Analysis of Change (pp.261-276). Mahwah, N.J.: Lawrence Erlbaum Associates.

Von der Lippe, A. (1998). Are conflict and challenge sources of personality development. En Sokoe, E., y Von der Lippe, A. (Ed.), Personality development in adolescence: A cross national and life span perspective (pp. 38-60). Londres: Routledge. 


\section{TABLES Y FIGURES}

Figure 1.Changes in Emotional Autonomy clusters between early and late adolescence

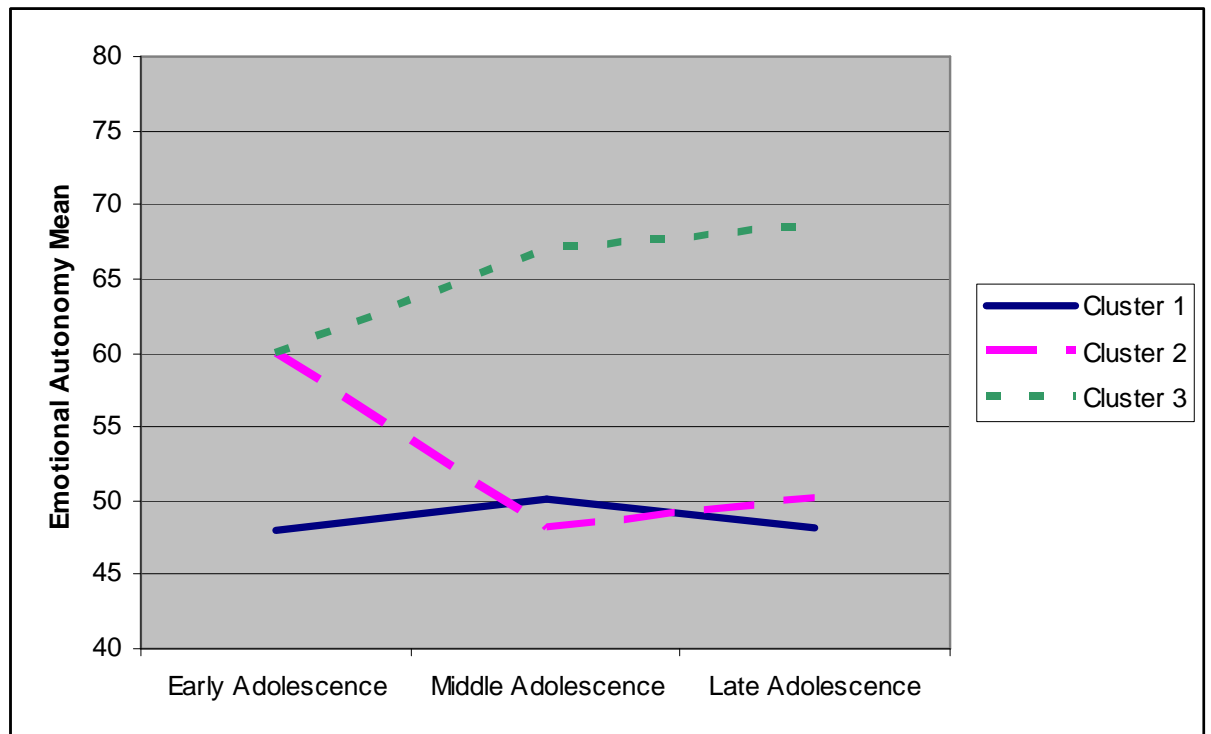

\begin{tabular}{l|c} 
& Frecuency \\
\hline Cluster 1 & 70 \\
Cluster 2 & 18 \\
Cluster 3 & 13
\end{tabular}


Table I. Correlations among Emotional Autonomy in T1 / T2 / T3

\begin{tabular}{lccc}
\hline Emotional Autonomy & $\mathrm{T} 1-\mathrm{T} 2$ & $\mathrm{~T} 2-\mathrm{T} 3$ & $\mathrm{~T} 1-\mathrm{T} 3$ \\
\hline Pearson Correlation & $\mathbf{. 3 9 * *}$ & $\mathbf{. 6 6}^{* *}$ & $\mathbf{. 4 4 * *}$
\end{tabular}

$* \mathrm{p}<.05 * * \mathrm{p}<.01$ 
Table II. Correlations among Emotional Autonomy dimensions in T1 / T2 / T3

\begin{tabular}{lccc}
\hline Emotional Autonomy & $\mathrm{T} 1-\mathrm{T} 2$ & $\mathrm{~T} 2-\mathrm{T} 3$ & $\mathrm{~T} 1-\mathrm{T} 3$ \\
\hline Individuation & $\mathbf{. 3 5} * *$ & $\mathbf{. 5 1} * *$ & $\mathbf{. 3 5} * *$ \\
Independency & $\mathbf{. 2 2 *}$ & $\mathbf{. 5 8 * *}$ & $\mathbf{. 2 0 *}$ \\
Deidealization & $\mathbf{. 3 9 * *}$ & $\mathbf{. 5 9} * *$ & $\mathbf{. 3 9 * *}$ \\
Parents as normal people & $\mathbf{. 4 0 * *}$ & $\mathbf{. 3 3} * *$ & $\mathbf{. 3 7 * *}$ \\
\hline
\end{tabular}

$* \mathrm{p}<.05 * * \mathrm{p}<.01$ 
Figure2. Changes in dimensions of Emotional Autonomy between early and late adolescence
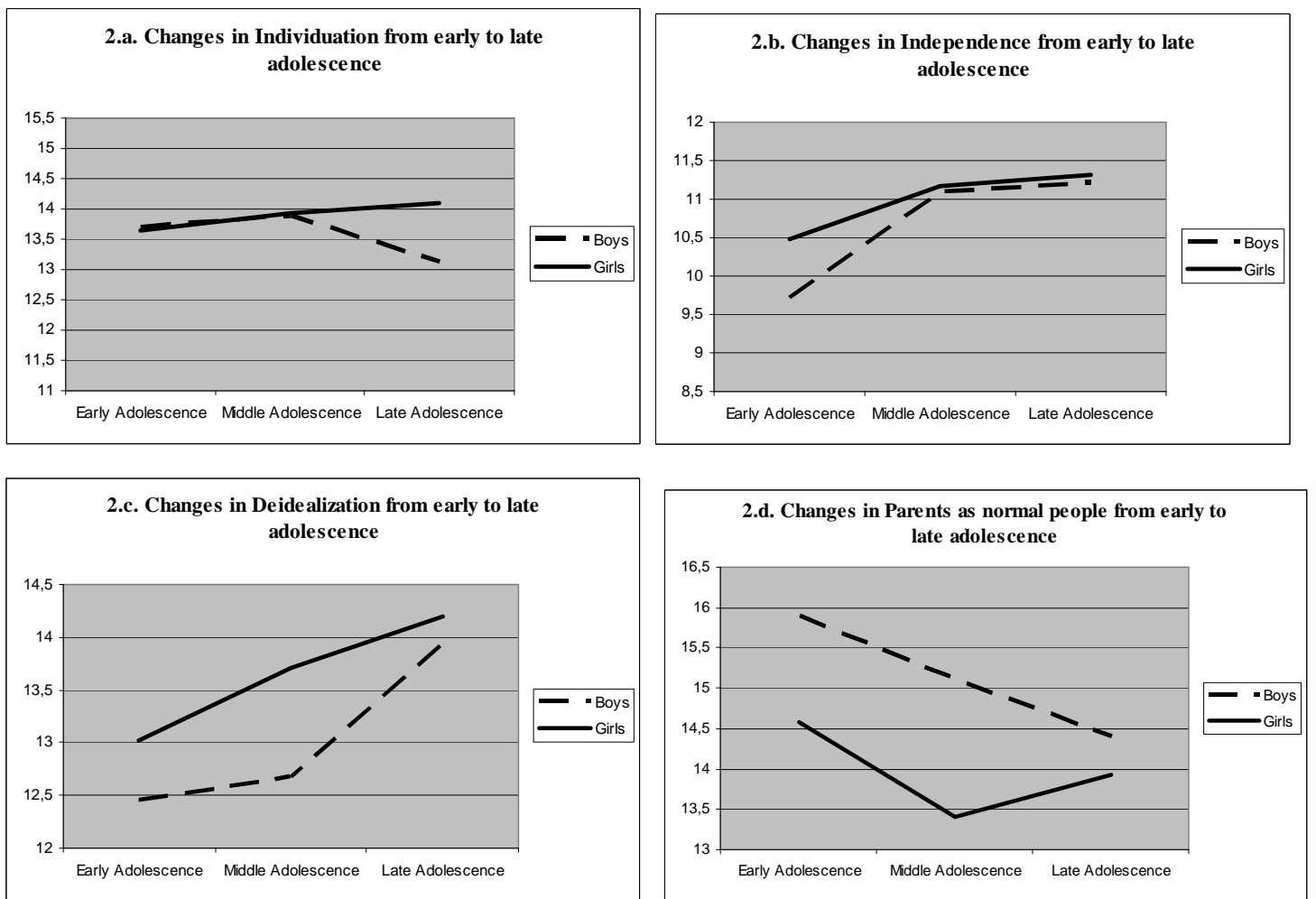
Table III. Correlations among Emotional Autonomy and Family functioning

\begin{tabular}{|c|c|c|c|c|c|c|c|c|}
\hline \multirow[b]{2}{*}{ Family T1 } & \multicolumn{4}{|c|}{ Emotional Autonomy } & \multicolumn{3}{|c|}{$\begin{array}{l}\text { Emotional } \\
\text { Autonomy }\end{array}$} & \multirow{2}{*}{$\begin{array}{l}\text { Emot. } \\
\text { Autono. } \\
\text { T3 }\end{array}$} \\
\hline & $\mathrm{T} 1$ & $\mathrm{~T} 2$ & T3 & Family T2 & $\mathrm{T} 2$ & $\mathrm{~T} 3$ & Family T3 & \\
\hline Communicat. & $-.31 * *$ & $-.30 * *$ & $-.23 *$ & Communicat. & $-.28 * *$ & $-.27 * *$ & Communicat. & $-.25 *$ \\
\hline Conflicts & $.35 * *$ & .07 & .05 & Conflicts & $.52 * *$ & $.46 * *$ & Conflicts & $.44 * *$ \\
\hline Affection & $-.31 * *$ & $-.27 * *$ & $-.29 * *$ & Affection & $-.33 * *$ & $-.34 * *$ & Affection & $-.44 * *$ \\
\hline Control & -.08 & -.09 & -.16 & Control & $-.28 * *$ & -.15 & Control & $-.27 * *$ \\
\hline Cohesion & $-.44 * *$ & -.14 & -.02 & Cohesion & $-.56 * *$ & $-.45 * *$ & Cohesion & $-.58 * *$ \\
\hline Adaptability & $-.34 * *$ & -.13 & -.09 & Adaptability & $-.51 * *$ & $-.31 * *$ & Adaptability & $-.44 * *$ \\
\hline
\end{tabular}


Table IV. Quality of family relationship according to Emotional Autonomy clusters

\begin{tabular}{lcccc}
\hline & $\begin{array}{c}\text { Cluster 1. } \\
\text { Stable and low }\end{array}$ & $\begin{array}{c}\text { Cluster 2. } \\
\text { Decreasing }\end{array}$ & $\begin{array}{c}\text { Cluster 3. } \\
\text { Increasing }\end{array}$ & $\mathrm{F}$ \\
\hline Quality of family relationship T1 & 103.71 & 91.22 & 92.17 & $\mathbf{7 . 9 7 * *}$ \\
Quality of family relationship T2 & 101.68 & 102.21 & 87.87 & $\mathbf{5 . 3 1 * *}$ \\
Quality of family relationship T3 & 102.08 & 102.01 & 85.97 & $\mathbf{7 . 3 6 * *}$ \\
\hline $\mathrm{p}<0.1, * \mathrm{p}<0.05, * * \mathrm{p}<0.01$ & & & &
\end{tabular}

